\title{
Removal of malachite green from aqueous solution using pulverized teak leaf litter: equilibrium, kinetic and thermodynamic studies
}

\author{
Emmanuel O. Oyelude ${ }^{1,2^{*}}$, Johannes A. M. Awudza ${ }^{1}$ and Sylvester K. Twumasi ${ }^{3}$
}

\begin{abstract}
The removal of malachite green (MG) from aqueous solution using teak leaf litter powder (TLLP) was investigated. The process was influenced by initial concentration, $\mathrm{pH}$ and temperature of dye solution as well as TLLP dosage. Optimum removal of MG per gram of TLLP occurred at $2 \mathrm{~g} / \mathrm{L}$ and at $\mathrm{pH}$ 6-8. Dubinin-Radushkevich and Freundlich isotherm models fit the batch adsorption data better than Langmuir isotherm. The monolayer capacity of TLLP was $333.33 \mathrm{mg} / \mathrm{g}$ at 293-313 K. The mean free energy of $7.07 \mathrm{~kJ} / \mathrm{mol}$ implied physical adsorption. The pseudo-second order model fit the kinetic data better than the pseudo-first order model. Both intraparticle diffusion and film diffusion mechanisms jointly influenced the adsorption process but the latter was the rate-controlling step. Thermodynamic data indicated that the process was endothermic, spontaneous and feasible. Therefore, TLLP could be an important low-cost adsorbent for removal of MG from aqueous solution.
\end{abstract}

Keywords: Adsorption, Malachite green, Teak leaf litter, Isotherm, Kinetics, Thermodynamics

\section{Introduction}

Malachite green (MG) is a synthetic triarymethane dye mainly employed for dyeing wool, silk, acrylic, leather, wood and paper [1]. It is also used in aquaculture as an ectoparasiticide and a fungicide because of its efficacy and low cost. The application of MG has been curtailed by some countries in recent years due to a number of toxicological concerns which are well documented. The dye is a possible carcinogen, tends to persist in the environment, and is toxic to aquatic and terrestrial organisms [2-4].

A number of methods are available for treating dyeimpacted wastewater. However, adsorption method using activated carbon is popular due to its simplicity and efficacy [5]. The main impediment to unfettered employment of the method is the high cost of commercial activated carbon and the extra cost incurred

\footnotetext{
*Correspondence: emmanola@gmail.com; eoyelude@uds.edu.gh 2 Department of Applied Chemistry and Biochemistry, University for Development Studies, Navrongo Campus, P.O. Box 24, Navrongo, Ghana

Full list of author information is available at the end of the article
}

in regenerating it. These have stimulated the interest of researchers to study non-conventional materials as cheaper and reliable substitutes for commercial activated carbon.

Forest plantations are established in Ghana mainly for production of fuel wood, electric poles, timber, environmental protection and reduction of rural poverty through employment generation. Teak, Tectona grandis, is among the most popular species of trees for reforestation in the country [6]. Plants contribute to nutrient cycling through litter fall. The factors that control litter production include: climate, age, size and species of trees; spacing of trees, type of forest, location and human activities $[7,8]$.

Rapid decomposition of litter assists to maintain soil fertility in tropical forest ecosystems [9]. The determinants of quality of any litter include: the specific weight and levels of carbon, nitrogen, lignin and polyphenols. Torreta and Takeda [10] indicated that, litter with C:N ratio greater than 30-40 may significantly reduce microbial activity leading to immobilization of nitrogen and impeded decomposition. Teak leaf litter (TLL) decomposes slowly due to a combination of its high $\mathrm{C}: \mathrm{N}$ ratio, 
which is normally greater than 50 ; and high specific weight.

A comparison of the quantities of litter fall under monoculture teak plantation forests in Nigeria revealed that between 3774 and $6043 \mathrm{~kg} / \mathrm{ha}$ litter was produced per annum [8]. Leaf litter accounts for at least $70 \%$ of the total litter fall [9]. It is estimated that an average of at least $3000 \mathrm{~kg} / \mathrm{ha}$ of teak leaf litter is expected annually in Ghana. This important biomass is abundantly available and inexpensive [11] but currently either left unused or burnt. This research focused on the feasibility of employing pulverized TLL to remove MG dye from aqueous solution. The impacts of equilibrium adsorption, kinetic and thermodynamic parameters on the overall adsorption process were investigated to shed light on the nature of the adsorption process.

\section{Experimental}

\section{Materials}

TLL was collected from a monoculture teak plantation at Navrongo, north-eastern Ghana. The sample was washed continuously with large volume of tap water until the wash water was colorless and finally rinsed with distilled water. It was then air-dried for 10 days and crushed using a clean blender. The pulverized sample was washed repeatedly with distilled water until the wash water was colorless. The TLL sample was filtered, dried overnight in an oven at $105{ }^{\circ} \mathrm{C}$. The cooled dry sample was then ground with a blender and sieved to obtain particles lesser than $210 \mu \mathrm{m}$. The sample was transferred into a glass bottle, tightly corked and labeled teak leaf litter powder (TLLP).

The MG (oxalate) dye used for the study was manufactured by Surechem Products Limited, Suffolk, England. The dye was used as supplied without any purification. A stock solution containing $1000 \mathrm{mg} / \mathrm{L}$ MG was prepared and dilute working solutions were prepared from the stock solution as appropriate. The maximum wavelength $\left(\lambda_{\max }\right)$ of dilute MG solution was found to be $620 \mathrm{~nm}$ using UV/visible spectrophotometer (Jenway, model 6305). Concentrated hydrochloric acid and sodium hydroxide pellets used were manufactured by Panreac Quimica S.A., Barcelona, Spain. Distilled water was used for the preparation of all reagents.

\section{Adsorption equilibrium}

Adsorption equilibrium tests were conducted for the removal of MG in aqueous solution using TLLP. Very dilute concentrations of the dye were first used to prepare a standard calibration plot use for the determination of the concentration of the dye samples. The effects of contact time, TLLP dose, $\mathrm{pH}$ of aqueous dye solution, temperature and concentration of MG dye were studied. For each test, a known mass of TLLP was weighed into a $250 \mathrm{~mL}$ stoppered Erlenmeyer flask, and a predetermined volume of MG solution of known concentration was added. The flask, with its content, was then shaken at $120 \mathrm{rpm}$ and dye samples withdrawn at regular time intervals or after equilibrium as appropriate. The withdrawn sample was centrifuged at $5000 \mathrm{rpm}$ for $5 \mathrm{~min}$ and the residual dye in the supernatant was determined by measuring its absorbance at $620 \mathrm{~nm}$ using UV/visible spectrophotometer (Jenway, model 6305). The quantity of MG, $\mathrm{q}_{\mathrm{e}}(\mathrm{mg} / \mathrm{g})$, removed from aqueous solution by TLLP was calculated from the following relationships:

$$
q_{e}=\frac{\left(C_{0}-C_{e}\right) V}{w}
$$

and

$$
R=\frac{\left(C_{0}-C_{e}\right) \times 100}{C_{0}}
$$

where, $\mathrm{C}_{0}$ and $\mathrm{C}_{\mathrm{e}}(\mathrm{mg} / \mathrm{L})$ are the initial and equilibrium concentration of MG, respectively; $\mathrm{V}(\mathrm{L})$ is the volume of the dye, $\mathrm{w}(\mathrm{g})$ is the mass of TLLP used; $\mathrm{q}_{\mathrm{e}}(\mathrm{mg} / \mathrm{g})$ and $\mathrm{R}$ (\%) is the quantity of MG removed from aqueous solution. All experiments were conducted at room temperature except for the study of the effect of temperature on the adsorption process. Each experiment was conducted in triplicate and the average values reported.

The effects of contact time and initial concentration of MG solution were studied together by adding $100 \mathrm{~mL}$ of dye solution to $1 \mathrm{~g}$ of TLLP in $250 \mathrm{~mL}$ Erlenmeyer flask. The initial concentration of the dye solution ranged between 50 and $200 \mathrm{mg} / \mathrm{L}$. The impact of the dose of TLLP on removal of MG dye from aqueous solution was studied by fixing the initial concentration and volume of dye at $100 \mathrm{mg} / \mathrm{L}$ and $100 \mathrm{~mL}$, respectively. The mass of TLLP was then varied from 0.05 to $1.00 \mathrm{~g}$. The effect of $\mathrm{pH}$ of $\mathrm{MG}$ solution was examined by fixing the initial concentration of MG and mass of TLLP at $200 \mathrm{mg} / \mathrm{L}$ and $0.20 \mathrm{~g}$, respectively. The $\mathrm{pH}$ of the dye solution was adjusted using $0.1 \mathrm{M} \mathrm{HCl}$ and $0.1 \mathrm{M} \mathrm{NaOH}$ solution. The initial volume of the dye used was $50 \mathrm{~mL}$ and the range of $\mathrm{pH}$ studied was $2-8 \mathrm{pH}$. The dye solution was partially decolorized and unstable at higher $\mathrm{pH}$ values. Calibrated pH meter (Crison, model Basic C20, Crison Instruments S.A., Barcelona, Spain) was used to take the readings. The effect of temperature of dye solution on its adsorption by TLLP was conducted by fixing initial concentration and volume of MG at $200 \mathrm{mg} / \mathrm{L}$ and $100 \mathrm{~mL}$, respectively. The dye solution was initially fixed at $\mathrm{pH} 6$ and the range of temperature studied was $20-40{ }^{\circ} \mathrm{C}$. 


\section{Adsorption kinetics}

The adsorption kinetics experiments were conducted using initial MG concentrations of 200, 400 and $800 \mathrm{mg} / \mathrm{L}$. The TLLP mass, temperature and initial $\mathrm{pH}$ of dye solution and volume of dye solution were kept constant at $1 \mathrm{~g}, 40{ }^{\circ} \mathrm{C}, 6.5$ and $100 \mathrm{~mL}$; respectively. The experiments were similar to those of batch equilibrium adsorption tests but dye samples were taken at regular intervals until the process reached equilibrium. The concentration of MG removed from aqueous solution by the adsorbent was determined using the equation below.

$$
q_{t}=\frac{\left(C_{0}-C_{t}\right) V}{w}
$$

where $\mathrm{q}_{\mathrm{t}}(\mathrm{mg} / \mathrm{g})$ is the quantity of MG solution at any time, $\mathrm{C}_{\mathrm{o}}(\mathrm{mg} / \mathrm{L})$ is the initial concentration of the aqueous solution of $M G, C_{t}(\mathrm{mg} / \mathrm{L})$ is the concentration of MG remaining in aqueous solution at any time, $\mathrm{w}$ is the mass of TLLP and V (L) is the volume of MG solution.

\section{Adsorption thermodynamics}

The thermodynamics experiments were similar to the kinetic tests except that the temperature of dye solution was varied between 20 and $40{ }^{\circ} \mathrm{C}$. The initial concentration and volume of the dye solution were fixed at $100 \mathrm{mg} / \mathrm{L}$ and $100 \mathrm{~mL}$, respectively; the initial $\mathrm{pH}$ of dye solution was adjusted to 6.5 while the mass of TLLP used was fixed at $0.2 \mathrm{~g}$. The concentration of the residual MG in solution was determined using Eq. (1).

\section{Results and discussion}

\section{Effect of contact time and initial concentration of MG}

The plot of the effect of contact time and initial concentration of MG is presented in Fig. 1. The removal of MG from aqueous solution by TLLP was very rapid within the first 5 min before slowing down, and gradually became constant on attaining equilibrium. The rapid uptake of the dye during the first stage could be attributed to the availability of large number of sites on the surface of the adsorbent to facilitate the adsorption process. There was a marked reduction in the speed of adsorption during the second stage because of significant decrease in the number of vacant surface sites available for adsorption. There was equally repulsion between dye molecules already adsorbed on the surface of the adsorbent and dye molecules in the aqueous phase. Similar results have been reported by other researchers who studied the removal of MG from aqueous solution by adsorbents $[1,12]$.

The contact time required for the process to attain equilibrium was dependent on the initial concentration of MG in aqueous solution. For the initial MG

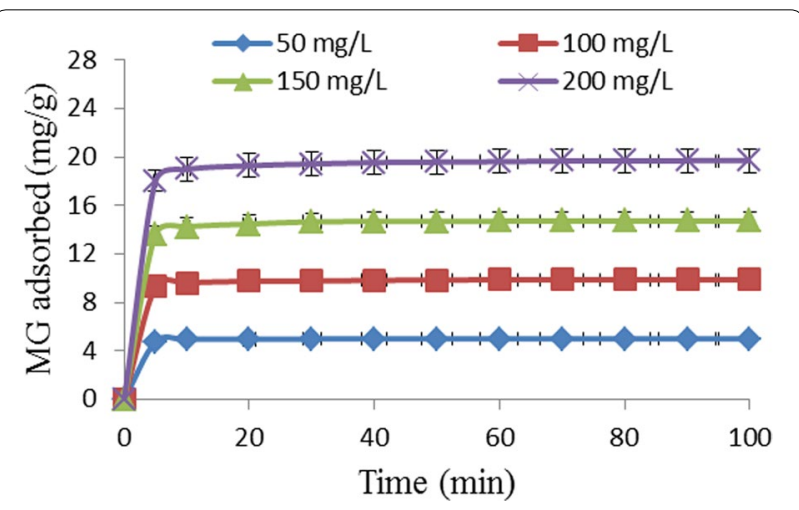

Fig. 1 Effect of contact time and initial concentration of dye on removal of MG by TLLP

concentration of $50,100,150$, and $200 \mathrm{mg} / \mathrm{L}$, the contact times required for the adsorption to attain equilibrium were: $30,60,70$, and $90 \mathrm{~min}$, respectively. The variation in the contact time required for adsorption to attain equilibrium could be explained on the basis of the boundary layer film the dye molecules must overcome to move from aqueous solution onto the surface of TLLP. Moreover, the dye molecules had to diffuse from the surface into the pores of the adsorbent. The more concentrated the dye solution, the more time it will take for dye molecules to move from the bulk solution into the pores of the adsorbent [13].

The adsorption capacity of TLLP was dependent on the initial concentration of the MG solution. The capacity of the adsorbent to remove dye molecules from solution increased from 4.99 to $19.70 \mathrm{mg} / \mathrm{g}$ when the initial concentration of MG solution was increased from 50 to $200 \mathrm{mg} / \mathrm{L}$. These results could be interpreted in terms of concentration gradient. This provided the driving force to overcome resistances to mass transfer of dye molecules from the solution, toward the surface of the adsorbent $[14,15]$.

\section{Effect of TLLP dosage}

The impact of TLLP dosage on the removal of MG from aqueous solution is shown in Fig. 2. The uptake of dye molecules increased from 33.76 to $98.19 \%$ as adsorbent dose was increased from 1 to $10 \mathrm{~g} / \mathrm{L}$. However, although the adsorption capacity increased marginally from 33.76 to $34.07 \mathrm{mg} / \mathrm{g}$ when the adsorbent dose was raised from 1 to $2 \mathrm{~g} / \mathrm{L}$, increase in dosage beyond $2 \mathrm{~g} / \mathrm{L}$ led to continuous decrease in the adsorption capacity of the adsorbent. The observation could be attributed to rapid superficial adsorption onto the surface of the adsorbent as TLLP to MG concentration ratio increased. The superficial adsorption did not favor optimum uptake of 


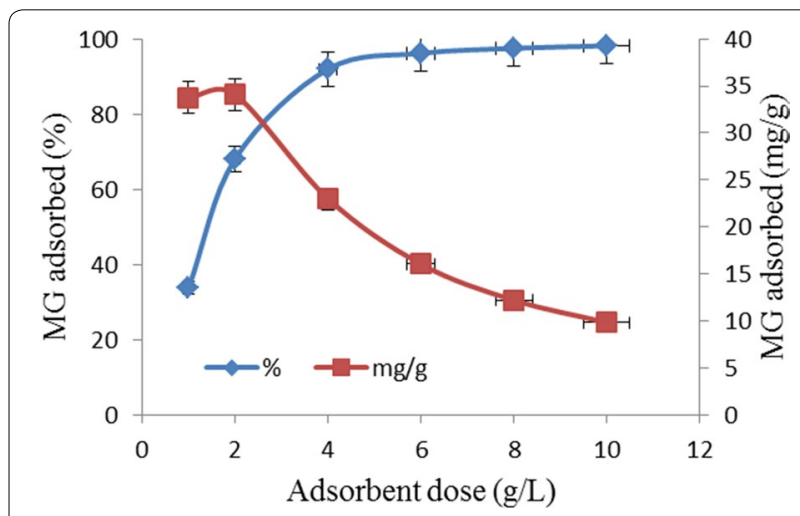

Fig. 2 Effect of TLLP dosage on removal of MG from solution

the dye molecules by the adsorbent. This was responsible for the decrease in adsorption capacity of TLLP as dosage increased. Other researchers who observed similar phenomenon include Hamdaoui et al. [14], Sun et al. [15] and Oyelude et al. [16].

\section{Effect of $\mathrm{pH}$ of MG solution}

$\mathrm{pH}$ plays important role in adsorption. The effect of $\mathrm{pH}$ of MG solution on adsorption is presented in Fig. 3. The uptake of MG by TLLP decreased sharply below $\mathrm{pH} 6$ but remained approximately constant from $\mathrm{pH} 6$ to 8 . The reduced uptake of the dye below $\mathrm{pH} 6$ was due to electrostatic repulsion between positively charged surface of the adsorbent and the positively charged cationic MG dye. The number of positively charged sites on the adsorbent increased as the $\mathrm{pH}$ reduced. Hence the adsorption of the dye molecules to the surface of the adsorbent reduced as $\mathrm{pH}$ was lowered $[1,17,18]$.

\section{Adsorption isotherms}

An adsorbate may not interact with different adsorbents in the same way. Isotherms are plots used to express the distribution of adsorbate molecules between two phases

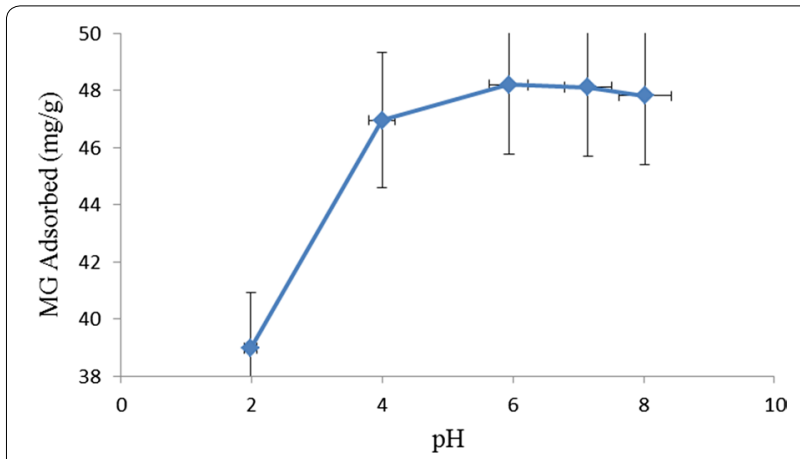

Fig. 3 Effect of $\mathrm{pH}$ of dye solution on removal of MG with respect to time. The removal of MG from aqueous solution by TLLP was studied using isotherm models of Langmuir [19], Freundlich [20] and Dubinin-Radushkevich [21].

Langmuir isotherm assumes constant adsorption energy and monolayer adsorption of adsorbate onto the surface of the adsorbent [19]. The linear form of the equation for the model is:

$$
\frac{C_{e}}{q_{e}}=\frac{1}{q_{m}} C_{e}+\frac{1}{q_{m}} \frac{1}{K_{L}}
$$

where $C_{e}(m g / L)$ is the concentration of MG adsorbed at equilibrium, $\mathrm{q}_{\mathrm{e}}(\mathrm{mg} / \mathrm{g})$ is the mass of MG adsorbed at equilibrium per unit mass of TLLP, $\mathrm{q}_{\mathrm{m}}(\mathrm{mg} / \mathrm{g})$ is a constant related to the monolayer adsorption capacity of the adsorbent, and $\mathrm{K}_{\mathrm{L}}(\mathrm{L} / \mathrm{mg})$ is the Langmuir constant related to the rate of adsorption. A straight-line plot of $\mathrm{C}_{\mathrm{e}} / \mathrm{q}_{\mathrm{e}}$ versus $\mathrm{C}_{\mathrm{e}}$ where slope equal to $\mathrm{C}_{\mathrm{e}} / \mathrm{q}_{\mathrm{e}}$ and intercept equals $\left(1 / q_{m}\right)\left(1 / K_{L}\right)$ is presented in Fig. 4. The values of $\mathrm{K}_{\mathrm{L}}, \mathrm{q}_{\mathrm{m}}, \mathrm{R}_{\mathrm{L}}$ and the linear correlation coefficient, $\mathrm{R}^{2}$, are presented in Table 1.

A dimensionless constant called separation factor, $\mathrm{R}_{\mathrm{L}}$, can be used to explain the essential characteristics of Langmuir equation. $R_{L}$ is defined as:

$$
R_{L}=\frac{1}{1+K_{L} C_{o}}
$$

where $\mathrm{K}_{\mathrm{L}}$ is the Langmuir adsorption constant $(\mathrm{L} / \mathrm{mg})$ and $C_{o}(\mathrm{mg} / \mathrm{L})$ is the highest initial concentration of MG. The adsorption process is only favorable if $0<R_{L}<1$, unfavorable if $R_{L}>1$, linear if $R_{L}=1$ and irreversible if $R_{L}=0$. The value of $R L$ for this present study was 0.0332 which indicates that the process was favorable.

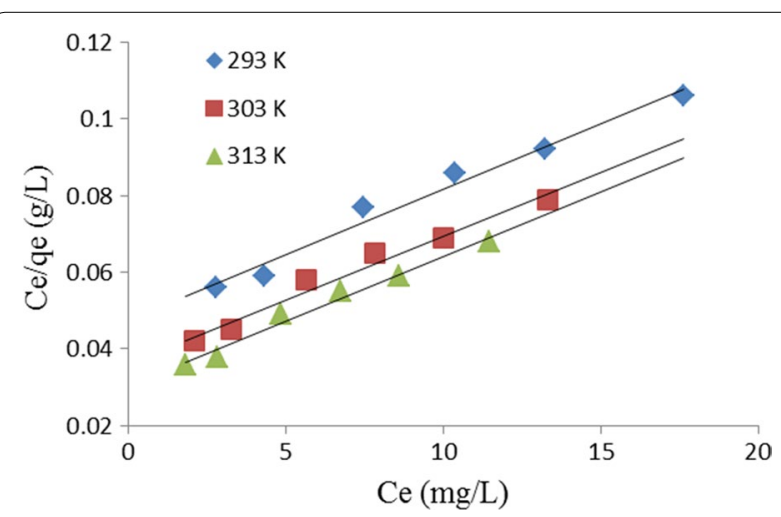

Fig. 4 Linearized Langmuir isotherm plot for removal of MG by TLLP 
Table 1 Isotherm constants for the adsorption of MG onto TLLP at pH 6.5

\begin{tabular}{|c|c|c|c|c|}
\hline Temperature (K) & $\mathrm{K}_{\mathrm{L}}(\mathrm{L} / \mathrm{mg})$ & $q_{m}(m g / g)$ & $\mathbf{R}_{\mathrm{L}}$ & $R^{2}$ \\
\hline \multicolumn{5}{|l|}{ Langmuir isotherm } \\
\hline 293 & 0.0638 & 333.33 & 0.0429 & 0.978 \\
\hline 303 & 0.0833 & 333.33 & 0.0332 & 0.975 \\
\hline 313 & 0.1000 & 333.33 & 0.0278 & 0.981 \\
\hline Temperature (K) & $K_{F}(m g / g)$ & $\mathrm{n}$ & $\mathrm{R}^{2}$ & \\
\hline \multicolumn{5}{|c|}{ Freundlich isotherm } \\
\hline 293 & 26.1216 & 1.5267 & 0.994 & \\
\hline 303 & 31.4051 & 1.5198 & 0.994 & \\
\hline 313 & 35.2371 & 1.5314 & 0.993 & \\
\hline Temperature (K) & $\mathrm{B}\left(\mathrm{mol}^{2} / \mathrm{J}^{2}\right)$ & $q_{D R}(\mathrm{mg} / \mathrm{g})$ & $\mathrm{E}(\mathrm{kJ} / \mathrm{mol})$ & $\mathrm{R}^{2}$ \\
\hline \multicolumn{5}{|c|}{ Dubinin-Radushkevich isotherm } \\
\hline 293 & $1.0 \times 10^{-8}$ & 348.50 & 7.07 & 0.996 \\
\hline 303 & $1.0 \times 10^{-8}$ & 418.91 & 7.07 & 0.993 \\
\hline 313 & $1.0 \times 10^{-8}$ & 435.57 & 7.07 & 0.997 \\
\hline
\end{tabular}

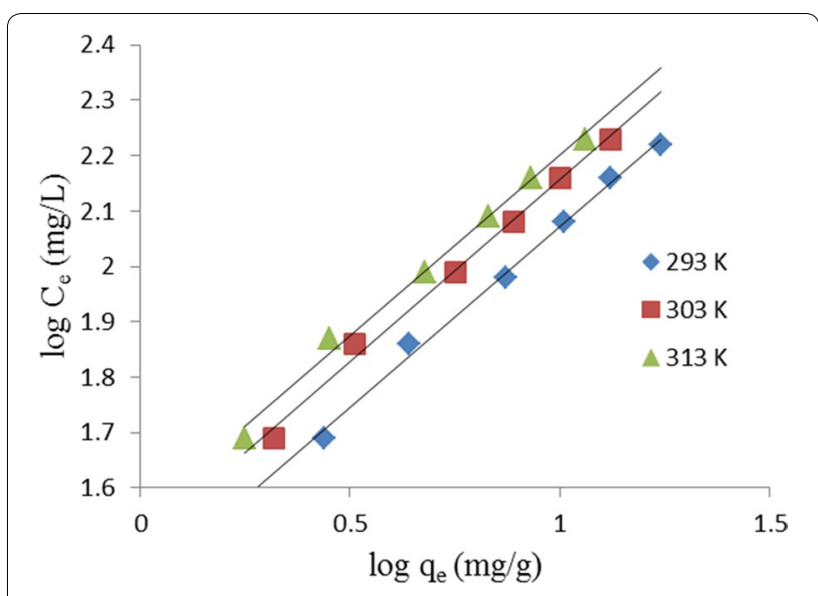

Fig. 5 Linearized Freundlich isotherm plot for removal of MG by TLLP

Freundlich isotherm assumes adsorption from bulk solution onto an adsorbent with heterogeneous surface [20]. The linear form of the equation for the model is:

$$
\log q_{e}=\frac{1}{n} \log C_{e}+\log K_{F}
$$

where $\mathrm{q}_{\mathrm{e}}$ and $\mathrm{C}_{\mathrm{e}}$ are as earlier defined, $\mathrm{K}_{\mathrm{F}}(\mathrm{mg} / \mathrm{g})(\mathrm{L} / \mathrm{mg})^{1 / \mathrm{n}}$ is a constant representing the adsorbent capacity and $1 / \mathrm{n}$ is a constant the heterogeneity factor. The numerical value of $1 / \mathrm{n}$ must be lesser than one for the adsorption to be favorable. A linear plot of $\log \mathrm{q}_{\mathrm{e}}$ against $\log \mathrm{C}_{\mathrm{e}}$ is shown in Fig. 5.

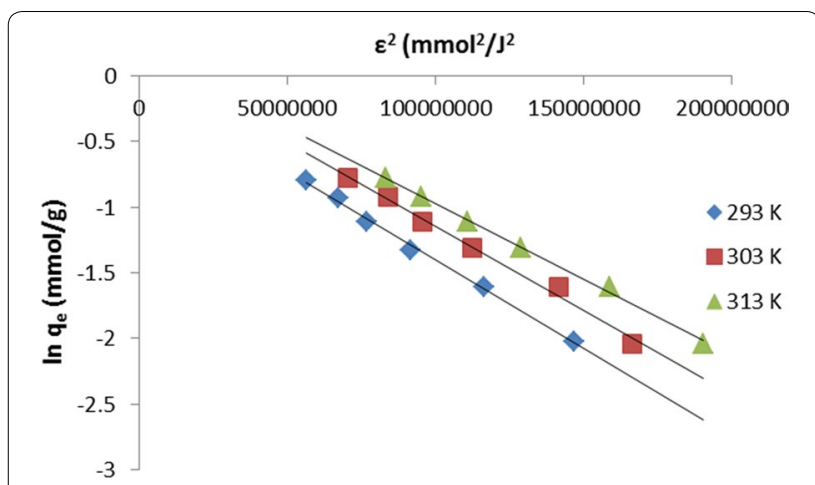

Fig. 6 Linearized Dubinin-Radushkevich isotherm plot for removal of MG by TLLP

The Dubinin-Radushkevich isotherm model [21] is used to determine the characteristic porosity of adsorbent and the mean free energy of adsorption. The isotherm assists to determine whether an adsorption is either physical or chemical in nature. The linear form of Dubinin-Radushkevich equation is:

$$
\ln q_{e}=\ln q_{D R}-\beta \varepsilon^{2}
$$

where $q_{D R}(\mathrm{mg} / \mathrm{g})$ is the Dubinin-Radushkevich maximum monolayer adsorption capacity, $\beta\left(\mathrm{mol}^{2} / \mathrm{J}^{2}\right)$ is a constant related to mean adsorption energy, and $\varepsilon$ is the Polanyi potential which is calculated using the following relationship:

$$
\varepsilon=R T \ln \left(1+\frac{1}{C_{e}}\right) .
$$


A plot of $\ln \mathrm{q}_{\mathrm{e}}$ against $\varepsilon^{2}$ is presented in Fig. 6. The values of $\beta$ and $q_{D R}$ were calculated from the slope and intercept of the plot, respectively. The mean free energy of adsorption is estimated from the value of $\beta$ using the equation below.

$$
E=\frac{1}{\sqrt{2 \beta}} .
$$

The value of $\mathrm{E}$ provides valuable information about the mechanisms of adsorption process. If $\mathrm{E}$ is lesser than $8 \mathrm{~kJ} / \mathrm{mol}$, the adsorption is regarded as physical in nature. However, if the value of $E$ lies between 8 and $16 \mathrm{~kJ} / \mathrm{mol}$, the adsorption is regarded as chemical or ion exchange in nature [22]. The mean adsorption free energy, E, was calculated as $7.07 \mathrm{~kJ} / \mathrm{mol}$ for this present study. This implies that the adsorption mechanism was physical in nature.

The summary of the isotherm constants and correlation coefficient, $\mathrm{R}^{2}$, for the three isotherm models applied for this study is presented in Table 1. On the basis of correlation coefficient alone, all the isotherm models fit the adsorption data well. However, DubininRadushkevich isotherm fits best followed by Freundlich and Langmuir isotherms in that order.

The reported monolayer adsorption capacities of selected low-cost adsorbents for MG are presented in Table 2. TLLP is a good adsorbent for MG based on the basis of its adsorption capacity which was estimated to be $333.33 \mathrm{mg} / \mathrm{g}$. It is worthy of note that temperature is one of the most important parameters that influence the uptake of dye molecules in aqueous solution. For this study, the uptake of MG from aqueous solution increased as temperature of dye solution increased irrespective of the initial concentration of the dye solution. This suggests that the adsorption process is endothermic in nature. This observation is attributed to the driving

Table 2 Comparison of the reported maximum monolayer adsorption capacities of selected adsorbents for MG

\begin{tabular}{lll}
\hline Adsorbent & $\mathbf{q}_{\mathbf{m}} \mathbf{( \mathbf { m g } / \mathbf { g } )}$ & References \\
\hline Teak leaf litter powder & 333.33 & This study \\
Commercial powder activated carbon & 222.22 & {$[24]$} \\
Dead leaves of plane tree & 97.09 & {$[14]$} \\
Chitosan beads & 93.5 & {$[25]$} \\
Bivalve shell-Zea mays L husk leaf & 81.5 & {$[18]$} \\
Rattan sawdust & 62.71 & {$[12]$} \\
Degreased coffee bean & 55.3 & {$[26]$} \\
Pineapple leaf powder & 54.64 & {$[27]$} \\
\hline
\end{tabular}

force of concentration gradient and increase in temperature which favored the endothermic process [23].

\section{Adsorption kinetics}

The kinetic of MG removal from aqueous solution were studied using pseudo-first order, pseudo-second order and intraparticle diffusion models. The equation for the pseudo-first order kinetic model [28] is:

$$
\log \left(q_{e}-q_{t}\right)=\log q_{e}-\frac{k_{1} t}{2.303}
$$

where $\mathrm{q}_{\mathrm{e}}(\mathrm{mg} / \mathrm{g})$ and $\mathrm{q}_{\mathrm{t}}(\mathrm{mg} /)$ are the quantity of dye adsorbed at equilibrium and time, $\mathrm{t}(\mathrm{min})$, respectively; and $k_{1}(1 / \mathrm{min})$ is the pseudo-first order rate constant. Figure 7 is a plot of $\log \left(\mathrm{q}_{\mathrm{e}}-\mathrm{q}_{\mathrm{t}}\right)$ against $\mathrm{t}$. The values of $\mathrm{k}_{1}$ and $\mathrm{q}_{\mathrm{e}}$ were determined from the slope $\left(\mathrm{k}_{1} / 2.303\right)$ and intercept $\left(\log \mathrm{q}_{\mathrm{e}}\right)$, respectively. The $\mathrm{R}^{2}$ values obtained from the plot ranged from 0.970 to 0.983 which implies that the pseudo-first order kinetic model had good fit for the adsorption process. The values of $\mathrm{k}_{1}$, qe and $\mathrm{R}^{2}$ are shown in Table 3.

Ho and McKay [29] expressed the equation for the pseudo-second order kinetic as follows:

$$
\frac{t}{q_{e}}=\frac{1}{k_{2} q_{e}^{2}}+\frac{1}{q_{e}} t
$$

where $k_{2}(g / m g$ min) is the rate constant. The plot of $t /$ $\mathrm{q}_{\mathrm{e}}$ against $\mathrm{t}$ is presented in Fig. 8 from which $\mathrm{q}_{\mathrm{e}}$ and $\mathrm{k}_{2}$ are determined from the slope and the intercept, respectively. The initial rate of adsorption, $\mathrm{h}(\mathrm{mg} / \mathrm{g} \mathrm{min})$, is calculated from the following equation:

$$
h=k_{2} q_{e}^{2} .
$$

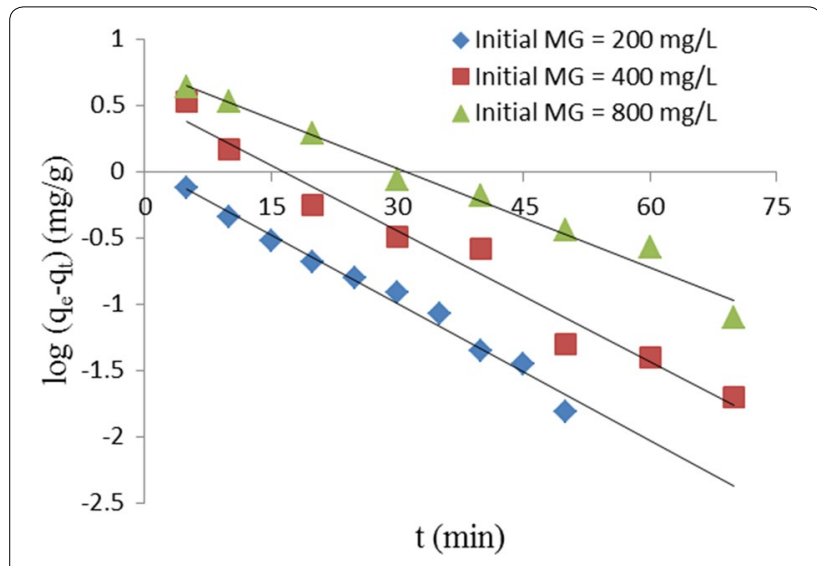

Fig. 7 Pseudo-first order kinetic plot for removal of MG by TLLP 
Table 3 Kinetic constants for removal of MG from aqueous solution by TLLP at different temperatures

\begin{tabular}{|c|c|c|c|}
\hline \multirow[t]{2}{*}{ Kinetic models } & \multicolumn{3}{|c|}{ Co (mg/L) } \\
\hline & 200 & 400 & 800 \\
\hline \multicolumn{4}{|l|}{ Pseudo-first order } \\
\hline $\mathrm{q}_{\mathrm{e}^{\prime}} \mathrm{mg} / \mathrm{g}$ & 1.102 & 3.524 & 5.929 \\
\hline $\mathrm{k}_{1}, 1 / \mathrm{min}$ & 0.015 & 0.014 & 0.010 \\
\hline$R^{2}$ & 0.983 & 0.970 & 0.979 \\
\hline \multicolumn{4}{|c|}{ Pseudo-second order } \\
\hline $\mathrm{q}_{\mathrm{e}} \mathrm{mg} / \mathrm{g}$ & 19.608 & 40.000 & 83.333 \\
\hline $\mathrm{k}_{2}, \mathrm{~g} / \mathrm{mg} \min$ & 0.260 & 0.089 & 0.029 \\
\hline $\mathrm{h}, \mathrm{mg} / \mathrm{g} \min$ & 99.963 & 142.880 & 199.999 \\
\hline$R^{2}$ & 1.000 & 1.000 & 0.999 \\
\hline \multicolumn{4}{|c|}{ Intraparticle diffusion } \\
\hline $\mathrm{k}_{\mathrm{int}}, \mathrm{mg} / \mathrm{g} \min ^{1 / 2}$ & 0.120 & 0.407 & 0.649 \\
\hline $\mathrm{C}, \mathrm{mg} / \mathrm{g}$ & 18.730 & 36.190 & 73.570 \\
\hline$R^{2}$ & 0.856 & 0.708 & 0.899 \\
\hline
\end{tabular}

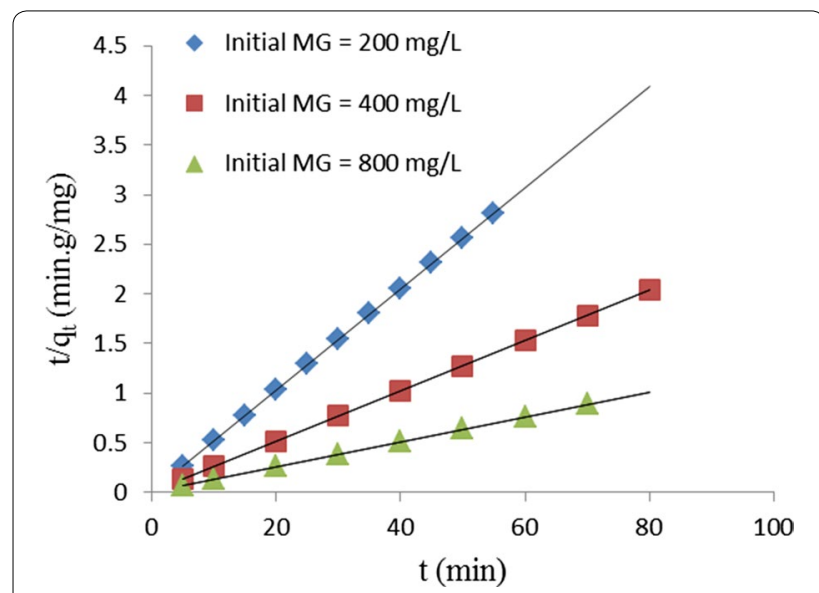

Fig. 8 Pseudo-second order kinetic plot for removal of MG by TLLP

The values of $R^{2}$ ranged between 0.999 and 1.000, which indicates that the adsorption of MG by TLLP perfectly fit the pseudo-second order kinetic model. The values of $k_{2}$, $\mathrm{q}_{\mathrm{e}}, \mathrm{h}$ and $\mathrm{R}^{2}$ are presented in Table 3 .

Intraparticle diffusion equation [30] is another important kinetic model commonly used to study adsorption kinetics. The intraparticle diffusion equation is:

$$
q_{t}=k_{i d} t^{1 / 2}+C
$$

where $k_{\mathrm{id}}\left(\mathrm{mg} / \mathrm{g} \mathrm{min}^{1 / 2}\right)$ is the intraparticle diffusion rate constant, $\mathrm{q}_{\mathrm{t}}(\mathrm{mg} / \mathrm{g})$ is the quantity of dye adsorbed at time $\mathrm{t}(\mathrm{min})$, and $\mathrm{C}(\mathrm{mg} / \mathrm{g})$ is the boundary layer thickness. The plot of $\mathrm{q}_{\mathrm{t}}$ against $\mathrm{t}^{1 / 2}$ shown in Fig. 9 is linear for every initial concentration of MG implying that the

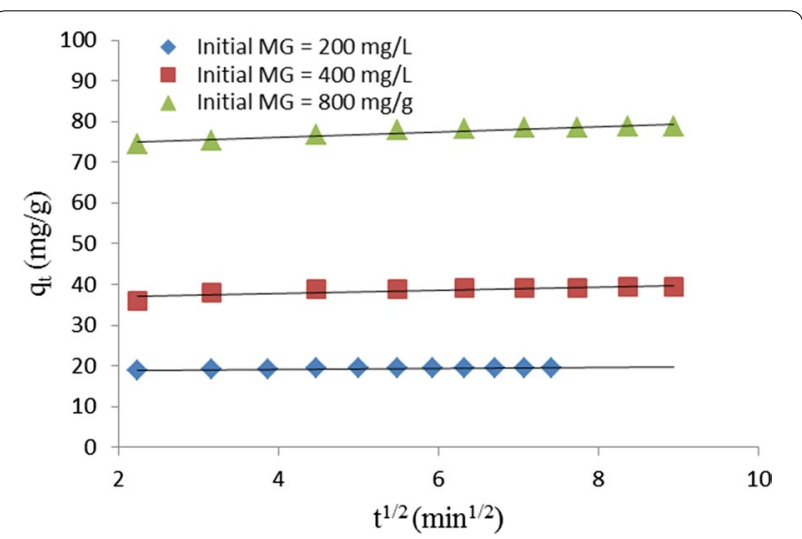

Fig. 9 Intraparticle diffusion kinetic plot for removal of MG by TLLP

adsorption process followed the intraparticle diffusion model. However, none of the plots passed through the origin indicating influence of boundary layer or film diffusion. The plot shows that the thickness of the boundary layer is proportional to the initial concentration of MG in aqueous solution. The values of $\mathrm{k}_{\mathrm{id}}, \mathrm{C}$ and $\mathrm{R}^{2}$ determined from the plots are shown in Table 3.

\section{Adsorption mechanism}

The mechanism for removal of dye molecules from aqueous solution may involve up to four steps. These steps include: bulk diffusion of molecules from solution to the surface of the adsorbent, boundary layer or film diffusion of molecules to the surface of the adsorbent, movement of molecules from the surface into the pores of the adsorbent or intraparticle diffusion and adsorption of dye molecules on active sites on the adsorbent through ion exchange, chelation and/or complexation [31].

It is clear from Fig. 9 that both intraparticle diffusion and film diffusion mechanisms take place at the same time in the uptake of MB by TLLP. The uptake of the dye by the adsorbent was very rapid within the first $5 \mathrm{~min}$ before slowing down, and gradually became constant on attaining equilibrium. Boyd model was used to further assess the kinetic data as to the rate-controlling step between intraparticle diffusion and film diffusion. The Boyd equation [32] is:

$$
\mathrm{F}=1-\frac{6}{\pi} \sum_{n=1}^{\infty} \frac{1}{n^{2}} \exp \left(-\mathrm{n}^{2} \mathrm{Bt}\right)
$$

and

$$
F=\frac{q_{t}}{q_{e}}
$$




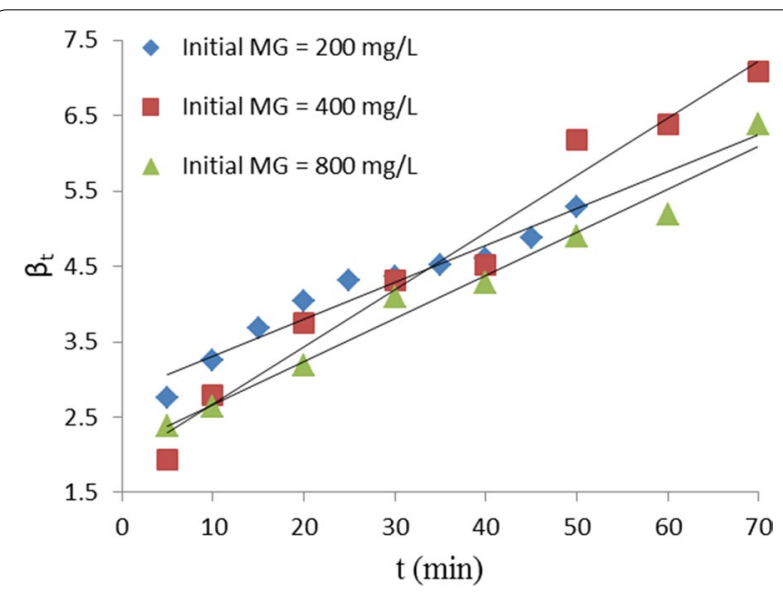

Fig. 10 Boyd plot for removal of MG by TLLP

where $\mathrm{F}$ equals the fractional attainment of equilibrium at time, $\mathrm{t}(\mathrm{min}), \mathrm{n}$ is the Freundlich constant, $\mathrm{Bt}$ is a function of $F$, and $\mathrm{q}_{\mathrm{t}}(\mathrm{mg} / \mathrm{g})$ and $\mathrm{q}_{\mathrm{e}}(\mathrm{mg} / \mathrm{g})$ represent quantity of dye adsorbed at time, $t$, and at equilibrium, respectively.

Reichenberg [33] proposed a simpler equation for calculating the values of $\mathrm{Bt}$ for each values of $\mathrm{F}>0.85$.

$$
B t=-0.4977-\ln (1-F) .
$$

The plot of Bt versus $t$ used to predict the mechanism of the adsorption process is presented in Fig. 10. The linear plot did not pass through the origin for every initial concentration of the dye in aqueous solution. This confirms that film diffusion was the rate-controlling step in the uptake of MG in aqueous solution by TLLP.

\section{Adsorption thermodynamics}

Standard enthalpy $\left(\Delta \mathrm{H}^{\circ}, \mathrm{kJ} / \mathrm{mol}\right)$, standard entropy $\left(\Delta \mathrm{S}^{\circ}\right.$, $\mathrm{J} / \mathrm{mol} \mathrm{K})$, and standard free energy $\left(\Delta \mathrm{G}^{\circ}, \mathrm{kJ} / \mathrm{mol}\right)$, are vital thermodynamics parameters that must be considered for proper assessment of any adsorption process. The following equations were employed to estimate their values for the studied temperature ranging between 293 and $313 \mathrm{~K}$.

$$
\begin{aligned}
& \Delta G^{\circ}=\Delta H^{\circ}-T \Delta S^{\circ} \\
& \Delta G^{\circ}=-R T \ln K_{d}
\end{aligned}
$$

where $\mathrm{R}$ is the gas constant $(8.314 \mathrm{~J} / \mathrm{mol} \mathrm{K}), \mathrm{T}(\mathrm{K})$ is temperature and

$$
K_{d}=q_{e} / C_{e}
$$

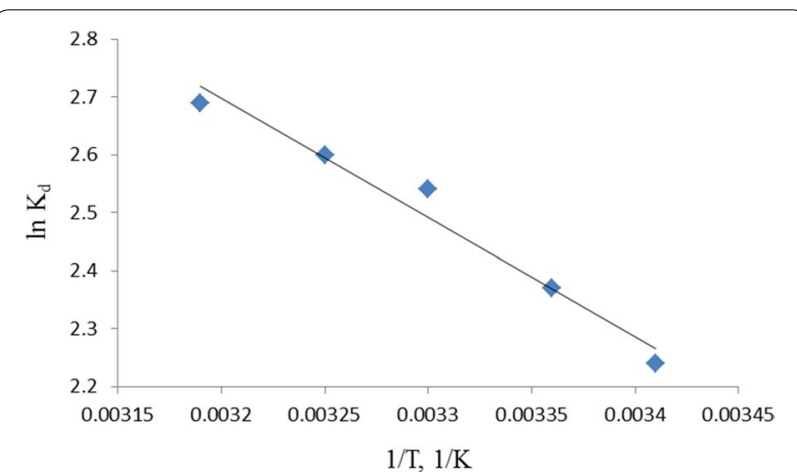

Fig. 11 Plot of $I n$ Kd versus $1 / T$ for removal of MG by TLLP

where $K_{d}$ is the distribution coefficient, $q_{e}(\mathrm{mg} / \mathrm{g})$ is the quantity of MG adsorbed at equilibrium and $\mathrm{C}_{\mathrm{e}}(\mathrm{mg} / \mathrm{L})$ is the quantity of MG remaining in solution at equilibrium. Equation (18) was used to estimate the values of $\Delta G^{\circ}$ at various temperatures. The equalization of Eqs. (17) and (18) produce:

$$
\ln K_{d}=\frac{\Delta S^{\circ}}{R}-\frac{\Delta H^{\circ}}{R T} .
$$

The plot of $\ln K_{d}$ versus 1/T shown in Fig. 11 is used for the estimation of the magnitudes of $\Delta \mathrm{H}^{\circ}$ and $\Delta \mathrm{S}^{\circ}$. The values of $\Delta \mathrm{H}^{\circ}, \Delta \mathrm{S}^{\circ}$ and $\Delta \mathrm{G}^{\circ}$ are presented in Table 4 . The values of $\Delta \mathrm{G}^{\circ}$ were negative at the range of temperature studied implying that the adsorption process was spontaneous and thermodynamically favorable. However, the positive value of $\Delta \mathrm{H}^{\circ}$ was positive indicating an endothermic process. The positive value of $\Delta S^{\circ}$ was a reflection of the increased randomness at the TLLP/MG solution interface due to the affinity of the adsorbent for the dye.

\section{Conclusion}

The removal of MG from aqueous solution revealed that the process was influenced by initial concentration, $\mathrm{pH}$ and temperature of dye solution as well as TLLP dosage. Optimum uptake of the dye per gram of the adsorbent occurred at $2 \mathrm{~g} / \mathrm{L}$ and at $\mathrm{pH}$ 6-10. Dubinin-Radushkevich and Freundlich isotherm models fit the batch adsorption data better than Langmuir isotherm. However, the monolayer capacity of TLLP for the removal of MG in aqueous solution was calculated to be $333.33 \mathrm{mg} / \mathrm{g}$ at $293-313 \mathrm{~K}$. The adsorption process was physical in nature because the mean free energy was $7.07 \mathrm{~kJ} / \mathrm{mol}$. 
Table 4 Thermodynamic parameters for the removal of MG from aqueous solution by TLLP

\begin{tabular}{|c|c|c|c|c|c|c|}
\hline \multirow[t]{2}{*}{$\Delta \mathrm{H}^{\circ}(\mathrm{kJ} / \mathrm{mol})$} & \multirow[t]{2}{*}{$\Delta \mathrm{S}^{\circ}(\mathrm{kJ} / \mathrm{mol} \mathrm{K})$} & \multicolumn{5}{|c|}{$\Delta \mathrm{G}^{\circ}(\mathrm{kJ} / \mathrm{mol})$} \\
\hline & & $293 \mathrm{~K}$ & $298 \mathrm{~K}$ & $303 \mathrm{~K}$ & $308 \mathrm{~K}$ & $313 \mathrm{~K}$ \\
\hline 17.069 & 0.077 & -1.964 & -2.138 & -2.348 & -2.447 & -2.575 \\
\hline
\end{tabular}

The pseudo-second order model fit the kinetic data much better than the pseudo-first order model. Intraparticle diffusion and film diffusion jointly influence the mechanism of adsorption. However, film diffusion was the rate-controlling step for the uptake of MG in aqueous solution by TLLP. Thermodynamic data indicated that the process was endothermic, spontaneous and feasible. Therefore, TLLP could be an important low-cost adsorbent for removal of MG from aqueous solution.

\begin{abstract}
Abbreviations
MG: malachite green; TLL: teak leaf litter; TLLP: teak leaf litter powder; C:N: carbon to nitrogen ratio; $\mathrm{q}_{\mathrm{e}}$ : mass of $\mathrm{MG}(\mathrm{mg})$ per gram of TLLP at equilibrium; $q_{\mathrm{t}}$ : mass of $M G(\mathrm{mg})$ per gram of TLLP at any time; $C_{\mathrm{o}}$ : initial concentration of $M G(\mathrm{mg} / \mathrm{L}) ; C_{e}$ : concentration of $M G$ remaining in aqueous solution at equilibrium (mg/L); $C_{t}$ : concentration of $M G$ remaining in aqueous solution at any time (mg/L); t: time (min); $\mathrm{V}$ : volume of aqueous solution of $M G(L) ; R$ : proportion of MG removed from aqueous solution (\%); T: temperature (Kelvin); $\mathrm{q}_{\mathrm{m}}$ : Langmuir isotherm monolayer adsorption capacity of TLLP $(\mathrm{mg} / \mathrm{g}) ; \mathrm{K}_{\mathrm{L}}$ : Langmuir isotherm constant; $R_{L}$ : linear correlation coefficient $\left(R^{2}\right) ; K_{F}$ : Freundlich isotherm constant; $1 / \mathrm{n}$ : heterogeneity factor of Freundlich isotherm; $\mathrm{q}_{\mathrm{DR}}$ : Dubinin-Radushkevich monolayer adsorption capacity of TLLP (mg/g); $\beta$ : constant related to mean free energy of adsorption; $\varepsilon$ : Polanyi potential; R: gas constant $(8.314 \mathrm{~J} / \mathrm{mol} \mathrm{K})$; E: mean free energy of adsorption; $\mathrm{k}_{1}$ : pseudo-first order kinetic rate constant; $\mathrm{k}_{2}$ : pseudo-second order kinetic rate constant; $h$ : initial rate of adsorption ( $\mathrm{mg} / \mathrm{g} \mathrm{min}$ ); $\mathrm{k}_{\mathrm{id}}$ : intraparticle diffusion rate constant; $\mathrm{F}$ : fractional attainment of equilibrium; Bt: function of $F ; \Delta H^{\circ}$ : change in standard enthalpy; $\Delta S^{\circ}$ : change in standard entropy; $\Delta G^{\circ}$ : change in standard free energy; $K_{d}$ : distribution coefficient.
\end{abstract}

\section{Authors' contributions}

This work is part of the doctorate research of EOO jointly supervised by JAMA and SKT at Kwame Nkrumah University of Science and Technology, Kumasi, Ghana. EOO designed the study and conducted all analyses. JAMA and SKT approved the study design and provided guidance during laboratory analyses. EOO wrote the first draft of the manuscript and JAMA and SKT contributed to the subsequent revisions. All authors read and approved the final manuscript.

\footnotetext{
Author details

${ }^{1}$ Department of Chemistry, Kwame Nkrumah University of Science and Technology, Kumasi, Ghana. ${ }^{2}$ Department of Applied Chemistry and Biochemistry, University for Development Studies, Navrongo Campus, P.O. Box 24, Navrongo, Ghana. ${ }^{3}$ Faculty of Public Health, Catholic University College, Fiapre, Sunyani, Ghana.
}

\section{Competing interests}

The authors declare that they have no competing interests.

Availability of data and materials

Not applicable.

\section{Consent for publication}

Not applicable.

Ethics approval and consent to participate

Not applicable.
Funding

No funding was received.

\section{Publisher's Note}

Springer Nature remains neutral with regard to jurisdictional claims in published maps and institutional affiliations.

Received: 6 February 2017 Accepted: 3 July 2018

Published online: 11 July 2018

\section{References}

1. Ahmad MA, Alrozi R (2011) Removal of malachite green dye from aqueous solution using rambutan peel-based activated carbon: equilibrium, kinetic and thermodynamic studies. Che Eng J 171:510-516

2. Alderman DJ (1985) Malachite green: a review. J Fish Dis 8:289-298

3. Culp SJ, Beland FA (1996) Malachite green: a toxicological review. J Am Col Toxicol 15(3):219-238

4. Srivastava S, Sinha R, Roy D (2004) Toxicological effects of malachite green. Aquatic Toxicol 66:319-329

5. Tan IAW, Ahmad AL, Hameed BH (2008) Adsorption of basic dye on high-surface-area activated carbon prepared from coconut husk: equilibrium, kinetic and thermodynamic studies. J Hazard Mat 154:337-346

6. Forestry Commission (2016) Ghana Forest Plantation Strategy: 20162040. http://www.fcghana.org/userfiles/files/Plantation\%20Annual\%20 Report/Ghana\%20Forest\%20Plantation\%20Strategy_24_01_16(2).pdf. Accessed 3 Feb 2017

7. O'Connell AM, Sankaran KV (1997) Organic accretion, decomposition and mineralization. In: Nambiar EKS, Brown AG (eds) Management of soil nutrient and water in tropical plantation forest. Canberra, ACIAR monograph No. 43 (XII), pp 443-573

8. Ojo AF, Kadeba TOS, Kayode J (2010) Litter mass and nutrient dynamics in a transformed rain forest ecosystem in southwestern Nigeria. Bangladesh J Sci Ind Res 45(4):351-358

9. Thakur TK, Thakur A (2014) Litter fall patterns of a dry tropical forest ecosystem of central India. Ecol Environ Conserv 20(3):1325-1328

10. Torreta NK, Takeda H (1999) Carbon and nitrogen dynamics of decomposing leaf litter during a 3.5-year decomposition. Eur J Soil Bio 36:81-89

11. Bello OS, Ahmad AM (2012) Coconut (Cocos nucifera) shell based activated carbon for the removal of malachite green from aqueous solution. Sep Sci Technol 47:903-912

12. Hameed BH, El-Khaiary MI (2008) Equilibrium, kinetics and mechanism of malachite green adsorption by activated carbon prepared from bamboo by $\mathrm{K}_{2} \mathrm{CO}_{3}$ activation and subsequent gasification with $\mathrm{CO}_{2}$. Hazard Mat 157:344-351

13. Hameed BH, Salman JM, Ahmad AL (2009) Adsorption isotherm and kinetic modeling of 2,4-D pesticide on activated carbon derived from date stones. J Hazard Mat 163:121-126

14. Hamdaoui O, Saoudi F, Chiha M, Naffrechoux E (2008) Sorption of malachite green by a novel sorbent, dead leaves of plane tree: equilibrium and kinetic modeling. Che Eng J 143:73-84

15. Sun X-F, Wang S-G, Liu X-W, Gong W-X, Bao N, Gao B-Y, Zhang H-Y (2008) Biosorption of malachite green from aqueous solutions onto aerobic granules: kinetic and equilibrium studies. Bioresour Technol 99:3475-3483

16. Oyelude EO, Frimpong F, Dawson D (2015) Studies on the removal of basic fuchsin dye from aqueous solution by $\mathrm{HCl}$ treated malted sorghum mash. J Mater Environ Sci 6(4):1126-1136 
17. Akar E, Altinişik A, Seki Y (2013) Using activated carbon produced from spent tea leaves for the removal of malachite green from aqueous solution. Ecol Eng 52:19-27

18. Jalil AA, Triwahyono S, Yaakob MR, Azmi ZZA, Sapawe N, Kamarudin NHN, Setiabudi HD, Jaafar NF, Sidik SM, Adam SH, Hameed BH (2012) Utilization of bivalve shell-treated Zea mays L. (maize) husk leaf as a low-cost biosorbent for enhanced adsorption of malachite green. Bioresour Technol 120:218-224

19. Langmuir $L$ (1918) The adsorption of gases on plane surfaces of glass, mica and platinum. J Am Chem Soc 40:1361-1403

20. Freundlich HMF (1906) Over the adsorption in solution. Journal of Phy Chem 57:385-470

21. Dubinin MM, Radushkevich L (1947) The equation of the characteristic curve of activated charcoal. Proceed Acad Sci Physical Chem Sec 55:331-333

22. Javadian H, Ghorbani F, Tayebi H-A, AsI SMH (2015) Study of the adsorption of $\mathrm{Cd}(\mathrm{II})$ from aqueous solution using zeolite-based geopolymer, synthesized from coal fly ash; kinetic, isotherm and thermodynamic studies. Arab J Chem 8:837-849

23. Bello OS, Ahmad MA, Ahmad M (2012) Adsorptive features of banana (Musa paradisiaca) stalk-based activated carbon for malachite green dye removal. Chem Ecol 28(2):153-167

24. Malik R, Ramteke DS, Wate SR (2007) Adsorption of malachite green on groundnut shell waste based powdered activated carbon. Waste Mgt 27:1121-1138
25. Bekçi Z, Özveri C, Seki Y, Yurdakoç K (2008) Sorption of malachite green on chitosan bead. J Hazard Mat 154:254-261

26. Baek M-H, ljagbemi CO, Se-Jin O, Kim D-S (2010) Removal of malachite green from aqueous solution using degreased coffee bean. J Hazard Mat $176: 820-828$

27. Chowdhury S, Chakraborty S, Saha P (2011) Biosorption of Basic Green 4 from aqueous solution by Ananas comosus (pineapple) leaf powder. Colloids Surf B Biointerfaces 84:520-527

28. Lagergren S (1898) About the theory of so-called adsorption of soluble substances. Kungliga SvenskaVetenskapsakademiens Handlingar 24:1-39

29. Ho YS, McKay G (1999) Pseudo-second order model for sorption processes. Process Biochem 34:451-465

30. Weber WJ, Morris JC (1963) Intraparticle diffusion during the sorption of surfactants onto activated carbon. J Sanit Eng Div Am Soc Civ Eng 89:53-61

31. Cheung WH, Szeto YS, MacKay G (2007) Intraparticle diffusion processes during acid dye adsorption onto chitosan. Bioresour Technol 98:2897-2904

32. Boyd GE, Adamson AW, Myers LS Jr (1947) The exchange adsorption of ions from aqueous solutions by organic zeolites. Part II: kinetics. J Am Chem Soc 69:2836-2848

33. Reichenberg D (1953) Properties of ion exchange resins in relation to their structure. Part III: kinetics of exchange. J Am Chem Soc 75:589-598

\section{Submit your manuscript to a SpringerOpen ${ }^{\odot}$ journal and benefit from:}

- Convenient online submission

- Rigorous peer review

- Open access: articles freely available online

- High visibility within the field

- Retaining the copyright to your article

Submit your next manuscript at $\boldsymbol{\nabla}$ springeropen.com 